\title{
Comparative Assessment of Antimicrobial Efficacy of Laboratory Prepared and Commercial Utensils and Floor Cleansers
}

\author{
Ragini Dubey*, Surinderjit Kaur, Param Pal Sahota and Inderjit Singh Grewal \\ Department of Family Resource Management, College of Home Science, \\ Punjab Agricultural University, Ludhiana (Punjab) India \\ *Corresponding author
}

\section{Keyw ords}

Antimicrobial, Efficacy, Minimum inhibitory

Concentration,

Bacterial growth

Article Info

Accepted:

26 August 2020

Available Online:

10 September 2020

\section{A B S T R A C T}

For assessing the antimicrobial efficacy of commercial and laboratory prepared utensils and floor cleansers, three most commonly used utensils cleansers and three floor cleansers were purchased from the market. Four types of cleansers i.e. 2 for utensils cleaning and 2 for floor cleaning were prepared in the laboratory. A total of 10 cleanser i.e. 5 for utensils and 5 for floor cleaning were tested for their antimicrobial efficiency using swabbing method. All the cleanser were also tested for their MIC i.e. (minimum inhibitory concentration). The finding of the research show that in case of laboratory prepared acidic as well as basic utensils cleansers, there was no bacterial growth when cleansers were applied in concentration of $2 \mathrm{ml}$ or more, similar were the result of commercial utensils cleanser UC-I while utensils cleansers UC-II and UC-III were unable to inhibit the microbes even upto $2 \mathrm{ml}$ concentration. Similarly in case of laboratory prepared acidic as well as basic floor cleansers bacterial growth was not detected when these were applied in concentration of $20 \%$ whereas none of the selected commercial floor cleansers was able to inhibit the bacterial growth on tiles at $20 \%$ concentration. The findings further revealed that laboratory prepared utensils and floor cleansers inhibited the growth of yeast and mold in all types of soiled surfaces tests and have better antimicrobial properties as compared to selected commercial utensils and floor cleansers. Therefore, these cleansers need to be promoted for wide spread use.

\section{Introduction}

Cleaning and disinfection of utensils and floors is an important task to prevent spread of infection which otherwise results in acute and chronic effects. Cleaning products are substances, be it liquid, solid or semi-solid which are used to remove dirt, including dust, micro-organism, stains, bad smells and clutter, in order to maintain health. Different types of cleaning products are available in market in powder, liquid or spray form. These synthetic cleansing products provide aesthetic and hygiene benefits, but these are also associated with health risks for the users and building occupants. Besides cleaning products, antimicrobial products have been effectively used to prevent transmission of disease 
causing micro-organism in home environment (Igbinosa et al., 2015). The main function of any cleanser is to clean / disinfect the surfaces by removing the bacteria or inhibiting their growth to minimum harmless level. Disinfection is a process where pathogenic microorganisms are removed or inactivated by chemical (e.g., chlorination) or physical (e.g., filtration, UV radiation) means so that they pose no significant risk of infection. An ideal disinfectant should have a broad spectrum of antimicrobial quality and it should be nontoxic and nonirritating. It should also be compatible with the surfaces to be disinfected, easy to prepare and use, stable, affordable and readily available and should not have any unpleasant odour.

Many chemical agents are now available commercially as disinfectants and antiseptics, composition of which includes halogen compounds, phenols and halogenated phenolic and substituted phenolic compounds. Considerable progress has been made in understanding of the mechanisms of antimicrobial actions of antiseptics and disinfectants (Russell and Chopra, 1996; Russell et al., 1997). The present study was aimed to determine the efficiency of formulated cleansers and minimum inhibitory concentration in comparison to commercially available most commonly used cleansers against microbial growth.

\section{Materials and Methods}

The description of procedure followed is as under

\section{Collection of cleansers}

Six most commonly used cleansers i.e. 3 utensils cleansers and 3 floor cleansers were purchased from the market. Two types of cleansers acidic and basic for utensils as well as for floor cleaning were prepared in the laboratory. The prepared cleansers were stored in the glass bottles at room temperature and prepared at their recommended use dilution in sterile distilled water on the day of the evaluation. All products were tested within the specified shelf-life. The selected commercial utensils and floor cleansers used in this study were labeled as UC-I, UC-II, UC-III; (commercial utensils cleansers) FC-I, FC-II and FC-III (commercial floor cleansers).

Procedure followed for testing antimicrobial efficiency of utensils and floor cleansers

For the purpose of evaluation of laboratory prepared and selected commercial utensils cleansers, four commonly used kitchen utensils of different materials, viz a serving plate and tea mugs of ceramic, a steel saucepan and pressure cooker were selected. For evaluation of floor cleansers, two commonly used floor tiles i.e ceramic and marble were selected for the experiments. The selected utensils and tiles were then soiled with four types of simulated soiling mixtures for starch stain, protein stains, tea stains and hard water stains which were prepared in the laboratory by modifying the method developed by American Society for Testing Material (ASTM). The soiled utensils were cleaned by following BIS standards (IS: 6047:2009) using all 5 cleansers i.e 2 laboratory prepared and 3 selected commercial utensils cleansers. Similarly soiled marble and ceramic tiles were washed using 2 laboratory prepared and 3 selected commercial floor cleansers. Thoroughly cleaned and dried utensils and tiles were subjected to microbial examination using following methods;

\section{Determination of antibacterial and antifungal effect of acidic and basic utensils and floor cleansers}

Bacteria on test surface were enumerated using the swabbing method (Downes and Ido, 2001). The test surfaces were scraped with two swabs coated with hydrophobic cotton 
which were dipped in Bacto D/E neutralizing broth (Difco) prior to neutralizing the effects of cleanser residue.

The swab heads were broken off into a plastic bottle. The cotton swabs in the bottle were blended with $5 \mathrm{ml}$ of buffer and shaken for 15 seconds to release the cells into the buffer.

Method for testing efficiency of laboratory prepared and commercial cleansers against microbial growth

Due to growing number of infection, it has become extremely important to establish effectiveness of sanitizing and cleansing power of the cleansing agent against environmental pathogens.

In order to decrease cost and improve sanitation, it is necessary to standardized minimum inhibitory concentration (MIC) of cleansing agents. In the present study a total of 10 cleansers i.e. 5 for utensils and 5 for floor were tested for inhibitory properties against microbial growth.

\section{Preparation of Media plates}

These were prepared using two media Nutrient Agar (NA) and Glucose Yeast Extract (GYE) was prepared. These were autoclaved at $\left(121^{\circ} \mathrm{C}\right)$ for 20 minutes. After autoclaving, these were dispensed in petriplates. Utensils cleansers direct application was done without any dilution.

The swab was taken from soiling plates (protein stains, starch stains and water attains) and soiling tiles (starch stains oil stains and water stains) before and after treatment of floor and utensils cleansers. The swab was spread on prepared NA and GYE. Plates were kept in BOD incubator at $37^{\circ} \mathrm{C}$ for $24-48$ hours for recovery of bacteria.

\section{Results and Discussion}

Efficacy and determination of minimum inhibitory concentration (MIC) of the utensil cleansers against microbial growth

In order to determine the efficacy and minimum inhibitory concentration of utensil cleansers under study a sterilized cotton swab was used to pick any possible microbes on the utensil even after treating it with the different concentration of the cleansers and grown over Nutrient agar and Glucose yeast extract. The antimicrobial activity of these cleansers was assessed by physically observing and comparing the growth of microbes with the control experiment. The findings are presented in the Table 1.

The findings show that in case of laboratory prepared acidic as well as basic cleansers bacterial growth was not detected when these were applied in concentration of $2 \mathrm{ml}$ or more.

These results were similar with UC-I while UC-II and UC-III cleansers were unable to check the growth even upto $2 \mathrm{ml}$ concentration. From these findings it can be concluded that laboratory prepared acidic and basic cleansers were having good antimicrobial properties.

\section{Efficacy and determination of minimum inhibitory concentration (MIC) of the floor cleansers against microbial growth}

The laboratory prepared and commercially selected cleansers were tested against microbes at three different concentrations i.e. $5 \%, 10 \%$ and $20 \%$.

For observing the microbial growth similar swab procedure as discussed under utensil cleansers was followed. The findings are summarized in the Table 2. 
The findings show that in case of laboratory prepared acidic as well as basic cleansers bacterial growth was not detected when these were applied in concentration of $20 \%$. However; none of commercially available cleanser was able to inhibit the bacterial growth on tiles at above specified concentrations. From these findings it can be concluded that laboratory prepared acidic and basic cleansers can be a best alternative to check bacterial growth on tiles.

\section{Comparative performance of different utensil cleansers in terms of checking microbial growth (yeast and mould) on two different media}

In this part of the study the swab was taken from soiling plates (protein stains, starch stains and water attains) and soiling tiles (starch stains oil stains and water stains) before and after treatment of the utensils cleansers under the test. The swab was spread on prepared NA and GYE. Then the plates were kept in BOD incubator at $37^{\circ} \mathrm{C}$ for $24-48$ hours for recovery of microbes. The findings in summarized form are presented in the Table 3.

The findings show that laboratory prepared acidic and basic cleansers inhibited the growth of yeast and mold in case of all types of soiled surfaces tested over two growth media. While in case of UC-I \& UC-III the growth of yeast and mould was observed for all type of soils over Glucose Yeast Extract while no growth was observed in case UC-I on Nutrient agar media. However UC-III was unable to check the growth of these microbes tested over the two media indicating that both the laboratory for acidic and basic cleansers were effective initiating the microbial growth while UC-I was effective inhibiting microbes in only NA media UC-III was not at all effective in removing microbes in all the media.

\section{Comparative performance of different Floor cleansers in terms of checking microbial growth (yeast and mould) on two different media}

For testing the laboratory prepared acidic and basic cleansers along with the commercial selected cleansers for their efficacy in checking growth of yeast and mould, the same procedure was followed as discussed in case utensil cleansers testing for the yeast and mold. The findings are presented in Table 4.

The findings show that laboratory prepared cleanser inhibited the growth of yeast and mold in case of all type of soiled surfaces and basic cleanser also checked growth of yeast and mold on most of the soiled surfaced except starch stain (tested over Glucose yeast extract media). However, all the selected commercial cleansers were unable to check the microbial growth when tested over Glucose Yeast Extract media.

The study proved that the both acidic and basic laboratory prepared utensils cleansers were more efficient in inhibiting the microbial growth, cleaning and sanitization of utensils than commercial cleaners UC-I, UC-II and UC-III. Similarly laboratory prepared acidic floor cleanser inhibited the growth of yeast and mold in case of all type of soiled surfaces and basic floor cleanser also checked growth of yeast and mold on most of the soiled surfaces except starch stain (tested over Glucose yeast extract media). However, all the selected commercial cleansers were unable to check the microbial growth when tested over Glucose Yeast Extract media. So, laboratory prepared utensils and floors cleansers need to be promoted as their antimicrobial efficiency is more as compared to commercial cleansers, besides, these are eco-friendly, health and packet-friendly. 
Table.1 Determination of minimum inhibitory concentration (MIC) of the utensil cleanser against microbial growth

\begin{tabular}{|c|l|c|c|c|}
\hline S.No. & Cleanser & \multicolumn{3}{|c|}{ Concentration of cleansing agents } \\
\cline { 3 - 5 } & & $\mathbf{1 m l}$ & $\mathbf{2} \mathbf{~ m l}$ & $\mathbf{3} \mathbf{~ m l}$ \\
\hline 1. & Control & $+\mathrm{ve}$ & $+\mathrm{ve}$ & $+\mathrm{ve}$ \\
\hline 2. & Acidic & $+\mathrm{ve}$ & $\mathrm{ND}$ & $\mathrm{ND}$ \\
\hline 3. & Basic & $+\mathrm{ve}$ & $\mathrm{ND}$ & $\mathrm{ND}$ \\
\hline 4. & UC-I & $+\mathrm{ve}$ & $\mathrm{ND}$ & $\mathrm{ND}$ \\
\hline 5. & UC-II & $+\mathrm{ve}$ & $+\mathrm{ve}$ & $\mathrm{ND}$ \\
\hline 6. & UC-III & $+\mathrm{ve}$ & $+\mathrm{ve}$ & ND \\
\hline
\end{tabular}

(ND-not detective inhibit bacterial growth) (+ve- positive bacterial growth)

Table.2 Determination of minimum inhibitory concentration (MIC) of the disinfectants floor cleanser against microbial growth

\begin{tabular}{|c|c|c|c|c|}
\hline \multirow{2}{*}{ S.No. } & \multirow{2}{*}{ Cleanser } & \multicolumn{3}{|c|}{ Concentration of cleanser (\%) } \\
\cline { 3 - 5 } & & $\mathbf{5}$ & $\mathbf{1 0}$ & $\mathbf{2 0}$ \\
\hline 1. & Control & $+\mathrm{ve}$ & $+\mathrm{ve}$ & $+\mathrm{ve}$ \\
\hline 2. & Acidic & $+\mathrm{ve}$ & $+\mathrm{ve}$ & $\mathrm{ND}$ \\
\hline 3. & Basic & $+\mathrm{ve}$ & $+\mathrm{ve}$ & ND \\
\hline 4. & FC-I & $+\mathrm{ve}$ & $+\mathrm{ve}$ & $+\mathrm{ve}$ \\
\hline 5. & FC-II & $+\mathrm{ve}$ & $+\mathrm{ve}$ & $+\mathrm{ve}$ \\
\hline 6. & FC-III & $+\mathrm{ve}$ & $+\mathrm{ve}$ & $+\mathrm{ve}$ \\
\hline
\end{tabular}

(ND-not detective inhibit bacterial growth) (+ve- positive bacterial growth)

Table.3 Comparative performance of different Utensil cleansers in terms of checking microbial growth (yeast and mould) on two different media

\begin{tabular}{|c|c|c|c|c|c|c|c|c|c|}
\hline \multirow{2}{*}{$\begin{array}{c}\text { S. } \\
\text { No. }\end{array}$} & \multirow[t]{2}{*}{ Cleanser } & \multicolumn{4}{|c|}{ Growth on GYE media } & \multicolumn{4}{|c|}{ Growth on NA media } \\
\hline & & $\mathbf{R}_{1}$ & $\mathbf{R}_{2}$ & $\mathbf{R}_{\mathbf{3}}$ & $\mathbf{R}_{\mathbf{4}}$ & $\mathbf{R}_{1}$ & $\mathbf{R}_{2}$ & $\mathbf{R}_{\mathbf{3}}$ & $\mathbf{R}_{\mathbf{4}}$ \\
\hline 1. & Control & $+\mathrm{ve}$ & +ve & +ve & +ve & $+\mathrm{ve}$ & + ve & +ve & $+\mathrm{ve}$ \\
\hline 2. & Acidic & ND & ND & ND & ND & ND & ND & ND & ND \\
\hline 3. & Basic & ND & ND & ND & ND & ND & ND & ND & ND \\
\hline 4. & UC-I & $+\mathrm{ve}$ & $+\mathrm{ve}$ & $+\mathrm{ve}$ & +ve & ND & ND & ND & ND \\
\hline 5. & UC-II & $+\mathrm{ve}$ & $+\mathrm{ve}$ & $+v e$ & $+v e$ & ND & ND & + ve & $+\mathrm{ve}$ \\
\hline 6. & UC-III & + ve & + ve & $+v e$ & $+v e$ & $+v e$ & $+\mathrm{ve}$ & $+v e$ & $+v e$ \\
\hline
\end{tabular}

Incubation time $-24 \mathrm{hr}$. Incubation temp $-37^{\circ} \mathrm{C}$. ND - Not detected, +ve growth $\mathrm{R}_{1}=$ Protein stain $; \mathrm{R}_{2}=$ Starch stain $; \mathrm{R}_{3}=$ Water stain $; \mathrm{R}_{4}=$ Tea stain 
Table.4 Comparative performance of different Floor cleansers in terms of checking microbial growth (yeast and mould) on two different media

\begin{tabular}{|c|c|c|c|c|c|c|c|}
\hline \multirow{2}{*}{$\begin{array}{c}\text { S. } \\
\text { No. }\end{array}$} & \multirow[t]{2}{*}{ Cleanser } & \multicolumn{3}{|c|}{ Growth on GYE media } & \multicolumn{3}{|c|}{ Growth on NA media } \\
\hline & & $\mathbf{R}_{1}$ & $\mathbf{R}_{2}$ & $\mathbf{R}_{\mathbf{3}}$ & $\mathbf{R}_{1}$ & $\mathbf{R}_{2}$ & $\mathbf{R}_{3}$ \\
\hline 1. & Control & $+v e$ & + ve & $+\mathrm{ve}$ & + ve & + ve & $+\mathrm{ve}$ \\
\hline 2. & Acidic & ND & ND & ND & ND & ND & ND \\
\hline 3. & Basic & ND & $+v e$ & ND & ND & ND & ND \\
\hline 4. & FC-I & $+v e$ & + ve & ND & ND & ND & ND \\
\hline 5. & FC-II & +ve & +ve & $+\mathrm{ve}$ & $+\mathrm{ve}$ & ND & ND \\
\hline 6. & FC-III & $+\mathrm{ve}$ & +ve & + ve & + ve & ND & ND \\
\hline
\end{tabular}

Incubation time $-24 \mathrm{hr}$. Incubation temp $-37^{\circ} \mathrm{C}$. ND - Not detected, +ve growth $\mathrm{R}_{1}=$ Oil stain $; \mathrm{R}_{2}=$ Starch stain $; \mathrm{R}_{3}=$ Water stain

\section{References}

Downes and Ido M (2001) Types and characteristics of disinfectants. J. Appl. Bacteriol30: 6-16

Igbinosa, E O Ibhazukor,Eribo M A (2015) Efficacy of household cleaning agents against some selected pathogenic bacteria. Afric. $J$ CLN EXPER MICROBIOL. 16(1):73-78.

Moses N Rosemary C Linda O and Nsikak S
(2013) Antimicrobial activity of some cleaning products against selected bacteria. Int Res J Pharm App Sci., 3:133-35.

Russell AD, Chopra I (1996) understanding antibacterial action and resistance. Afr.J. Pharma. Pharmacol. 2:186-190.

IS 6047:2009 Scouring products for utensils cleaning specification.ICS.100.40; 97.040.60.

\section{How to cite this article:}

Ragini Dubey, Surinderjit Kaur, Param Pal Sahota and Inderjit Singh Grewal. 2020. Comparative Assessment of Antimicrobial Efficacy of Laboratory Prepared and Commercial Utensils and Floor Cleansers. Int.J.Curr.Microbiol.App.Sci. 9(09): 3534-3539. doi: https://doi.org/10.20546/ijcmas.2020.909.438 